\title{
Effectiveness of Planned Teaching Programme on Knowledge Regarding Prevention of Vitamin A Deficiency among the Mothers of Under Five Children in Selected Rural Areas of Vidharbha Region
}

\author{
Vishakha Ganvir \\ Assistant professor, Godavari College of Nursing, Jalgaon, Maharashtra, India
}

\begin{abstract}
Vitamin A deficiency is one of the most widespread nutritional deficiencies worldwide; the research results suggest that dietary intake rich with vitamin A is highly efficacious in improving vitamin A status among populations at risk of vitamin A deficiency. This study was based on descriptive Evaluative approach. The method used for this study was Quasi experimental one group pretest post test research design. Based on the objectives and the hypothesis the data were analyzed by using various statistical tests. Analysis of data showed that there is significant difference between pre test and post test knowledge. The calculated ' $t$ ' values are much higher than the tabulated values. Hence it is statistically interpreted that the planned teaching programme on prevention of vitamin A deficiency among the mothers of under five children was effective.
\end{abstract}

Keywords: Vitamin A, Night blindness, Xeropthalmia, Prevention of vitamin A deficiencies, Under five children

\section{Introduction}

Jawaharlal Nehru once said," Children's are the wealth of tomorrow; take care of them if you wish to have strong India, and be ready to meet various challenges". ${ }^{1}$

Vitamin A deficiency is one of the major public health problems in our country and contributes to preventable blindness among young children. ${ }^{2}$ The most rational approach to the control of prevention of Vitamin A deficiency is to ensure that diets provide adequate amounts of the Vitamin. Vitamin A deficiency affects growth, the differentiation of epithelial tissues, and immune competence. The most dramatic impact, however, is on the eye and includes night blindness, xerosis of the conjunctiva and cornea, and ultimately corneal ulceration and necrosis of the cornea. ${ }^{3}$ The most important step in preventing vitamin A deficiency is ensuring that children's diets include adequate amounts of carotene containing cereals, tubers, vegetables, and fruits. Proper diet and vitamin A prophylaxis and home gardening are also very necessary to prevent vitamin A deficiencies specifically at controlling blindness arising from Vitamin A deficiency. ${ }^{4}$ Approximately 7 million pregnant women are vitamin A deficient. Health consequences of vitamin A deficiency include mild to severe (blinding) stages of xerophthalmia, and increased risk of mortality. Globally, 4.4 million preschool children have xerophthalmia and 6 million mothers suffer night blindness during pregnancy. Both conditions are associated with increased risk of morbidity and mortality. Epidemiologic data on vitamin A deficiency disorders can be useful in planning, designing, and targeting interventions. ${ }^{5}$

\section{Literature Survey}

Conservative estimates project over 500,000 cases/year of new active corneal lesions and 6-7 million cases of noncorneal xerophthalmia attributable to vitamin A deficiency on a worldwide basis. ${ }^{6}$ A short-term, emergency measure includes the administration to vulnerable groups of single, large doses of vitamin A on a periodic basis. In the medium-term, the fortification of a dietary vehicle (e.g., sugar or monosodium glutamate) with vitamin A can be initiated. The World Health Organization plans to launch a 10 -year program of support to countries where vitamin A deficiency is a significant public health problem.

In 1995, the World Health Organization estimated 254 million children to be Vitamin A deficient and 2.8 million to have xerophthalmia. Subsequently, estimates were changed to 75-140 million and 3.3 million, respectively. ${ }^{7}$

Using vital statistics compiled by UNICEF, we derived population figures and mortality rates for under-5-year children. The findings of vitamin A supplementation trials were applied to populations at-risk of endemic vitamin A deficiency to estimate the potential impact of improved vitamin A nutrient in reducing mortality during preschool years. ${ }^{8}$ Improved vitamin A nutrient would be expected to prevent approximately 1-2 million deaths annually among children aged 1-4 years. An additional 0.25-0.5 million deaths may be averted if improved vitamin A nutrient can be achieved during the latter half of infancy. Improved vitamin A nutrient alone could prevent 1.3-2.5 million of the nearly 8 million late infancy and preschool-age child deaths that occur each year in the highest-risk developing countries. ${ }^{9}$ Approximately 127 million under five children are vitamin A deficient. Conditions are associated with increased risk of 


\section{International Journal of Science and Research (IJSR) \\ ISSN (Online): 2319-7064 \\ Index Copernicus Value (2013): 6.14 | Impact Factor (2015): 6.391}

morbidity and mortality. While reductions of child mortality of $19-54 \%$ following vitamin A treatment have been widely reported, more recent work suggests that dosing newborns with vitamin $\mathrm{A}$, in some settings, may lower infant mortality. $^{10}$

\section{Problem Definition}

A study to assess the effectiveness of planned teaching programme on knowledge regarding prevention of vitamin A deficiency among the mothers of under five children in selected Rural areas of Vidharbha region.

\section{Objective:}

1) To assess the existing knowledge regarding prevention of vitamin A deficiency among the mother's of under five children.

2) To assess the effectiveness of planned teaching on knowledge regarding prevention of vitamin A deficiency among the mother's of under 5 children.

3) To associate the knowledge score with selected demographic variables.

\section{Methodology/Approach}

A single group pre test and post test (quasi-experimental) design was chosen for the study. In the present study a pre test was administered by means of structured questionnaire depicted as $\mathrm{P}_{1}$ and then planned teachimg programme was given depicted as $\mathrm{X}$, a post test was conducted using the same structured questionnaire depicted $\mathrm{P}_{2}$. The study design is depicted as -

\begin{tabular}{|c|c|c|}
\hline Pre Test & Planned teaching programme & Post Test \\
\hline $\mathrm{P}_{1}$ & $\mathrm{X}$ & $\mathrm{P}_{2}$ \\
\hline
\end{tabular}

An descriptive Evaluative approach was found to be more appropriate to assess the knowledge gain. The proposed study was undertaken in at selected rural areas of vidharbha region namely; palothi, and salod ( hirapur) village area in Wardha district. The population and samples were mothers of under five children of selected rural area who were fulfilling the inclusion and exclusion criteria and the sample consisted of sixty mothers. The sampling technique used in this study was non-probability convenient sampling. Tools used for data collection include two section namely demographic variable and structured knowledge questionnaires.

\section{Result}

A structured questionnaire is used for data collection. The analysis was done with the help of descriptive and inferential statistics.

\begin{tabular}{|c|c|c|c|}
\hline S. N. & Data analysis & Method & Remark \\
\hline & $\begin{array}{l}\text { Descriptive } \\
\text { statistics }\end{array}$ & $\begin{array}{c}\text { Mean, standard } \\
\text { deviation,perce- } \\
\text { ntage. }\end{array}$ & $\begin{array}{c}\text { Knowledge regarding } \\
\text { prevention of vitamin A } \\
\text { deficiency. }\end{array}$ \\
\hline & \multirow[b]{2}{*}{$\begin{array}{l}\text { Inferential } \\
\text { statistics }\end{array}$} & Paired " $t$ " test & $\begin{array}{c}\text { Effectiveness of planned } \\
\text { teaching }\end{array}$ \\
\hline & & $\begin{array}{l}\text { Unpaired "t" test } \\
\text { and one way } \\
\text { ANOVA }\end{array}$ & $\begin{array}{c}\text { Associate demographic } \\
\text { variables with level of } \\
\text { knowledge }\end{array}$ \\
\hline
\end{tabular}

The data was analyzed and is presented in the following sections:-

Section I: Distribution of sample in relation to demographic data.

Section II: assessing the existing knowledge of mothers of under five children regarding prevention of vitamin A deficiency in under five children.

Section III: evaluate the effectiveness of planned teaching programme on prevention of vitamin a deficiency in under five children

Section IV: Association of knowledge score with demographic variables

\begin{tabular}{|c|c|c|c|c|c|}
\hline Overall & $\begin{array}{c}\text { Mean } \\
\text { knowledge } \\
\text { score }\end{array}$ & SD & $\begin{array}{c}\text { Mean } \\
\text { percentage }\end{array}$ & $\begin{array}{c}\mathrm{t} \text { - } \\
\text { value }\end{array}$ & p-value \\
\cline { 1 - 4 } Pre Test & 9.96 & 2.24 & 45.30 & 25.13 & $\begin{array}{c}0.000 \\
\text { S,p }<0.05\end{array}$ \\
\hline Post Test & 17.18 & 1.20 & 78.10 & 20 \\
\hline
\end{tabular}

The $\mathrm{P}$ value is less than the level of significance that is 0.05 . This indicates that the gain in post test knowledge is significant. It proves the significance of planned teaching programme in the improvement of the knowledge statistically.

In this study marked improvement of scores in the post test as $61.67 \%$ of samples had good score and $38.33 \%$ of samples had excellent and average scores. It means planned teaching programme is effective.

There is no significant association between age, education, religion, number of children, monthly family income, age of the child, occupation, information about prevention of vitamin A deficiency.

\section{Discussion}

The finding of the study was discussed with reference to the objectives and with the findings of the other studies in this section. The present study was undertaken to assess the effectiveness of planned teaching programme on knowledge regarding prevention of vitamin A deficiency among the mothers of under five children in selected Rural areas of vidharbha region.

Launched by a UN interagency meeting in October 1985, the programme focuses on 34 developing countries known to have serious vitamin A deficiency problems. Despite unprecedented agreement on the need for the programme, however, the SCN annual session in February 1987 noted with concern that commitment of resources has been with few exceptions slow and requests for assistance from national governments limited in number and scope. ${ }^{11}$

Centers for Disease Control and Prevention (CDC) Vitamin A deficiency among children--Federated States of Micronesia, 2000, Literature is available on certain of these issues, such as the Vitamin A, a fat-soluble, heat-stable nutrient (retinol) derived from animal sources and certain fruits and vegetables that forms the basic component of retinal pigments and plays a vital role in optimal health, growth, and development. Vitamin A deficiency (VAD) can substantially increase the 


\section{International Journal of Science and Research (IJSR) \\ ISSN (Online): 2319-7064 \\ Index Copernicus Value (2013): 6.14 | Impact Factor (2015): 6.391}

risk for childhood mortality from infectious and noninfectious causes. $^{12}$

This study suggests that vitamin A supplementation is not needed only for under five children it also necessary for pregnant women to avoid or prevent vitamin A deficiency.

So it is important public issue regarding Vitamin A deficiency in under five children, most of the studies show that if we plan properly and improve the nutritional status along with vitamin A supplementation it will help to reduce the vitamin A deficiency in under five children and also reduce the mortality and morbidity.

\section{Conclusion}

The planned teaching programme significantly brought out improvement in the knowledge of mothers regarding prevention of vitamin A deficiency in under five children. Analysis of data showed that there was significant difference between pre tests and post test knowledge score and there is no significant association between demographic variable.

\section{Future Scope}

The future scope of this study has implications for nursing administration, nursing education, nursing research and nursing practice.

\section{Nursing Services}

Nurses working in the child health nursing and community set up can benefit from such researches, as it will provide more insight regarding the preventive of vitamin A deficiency in under five children. They should know the importance of the preventive aspect with regard to vitamin A deficiencies in under five children.

\section{Nursing Education}

The nursing teachers can use the result of the study as an informative illustration for the students. Nursing education should help in inculcating values and a sense of responsibility in the students to educate the mothers of under five children and to foster the practice of health education to promote and prevent under five children from vitamin A deficiencies.

\section{Nursing Administration \\ Nursing administration can depute nurses for various workshops, conferences, and special courses; and also in- service education programs can be arranged for the nursing staff. The findings of the study should be used as a basis of in-service education programs for nurses so as to make them aware of the present problems in the society.}

\section{Nursing research}

Nursing research is an essential aspect of nursing as it uplifts the profession and develops new nursing norms and a body of knowledge. Another research has been added to the Nursing literature. Very few studies have been done on a similar basis. The research design, findings and the tool can be used as avenues for further research.
There is a need for extended and intensive nursing research in the area of health education for mothers of under five children to improve their knowledge for better health of under five child and prevent them from vitamin A deficiencies and make child healthy and productive citizens.

\section{References}

[1] Gogate P, Kishore H, The pattern of childhood blindness ;Indian Journal of Public Health, vol.16 ,page no. 12-13 , 2009 Jul-Aug.

[2] Dr. John Anne. Vitamin A deficiency- treatment and Prevention; health vitamins guide.com 29 feb 2011.

[3] Audrey Berman and Shirlee Snyder ; Prevalence and Incidence of Vitamin A deficiency, Professional Guide to Diseases ,Eighth Edition,2005.

[4] Beaton GH, Martorell R, L'Abbé, et al. Effectiveness of vitamin A supplementation in the control of young child morbidity and mortality. UN, ACC/SCN State-of-theart Series, Nutrition policy Discussion Paper No. 13, 1993.

[5] Polit Denise F. and Bernadette P. Hungler. Nursing research principal and method. $4^{\text {th }}$ edition. Vol . J. B. Lippincott Company.

[6] Christopher P. Howson, Eileen T. Kennedy, and Abraham Horwitz, Prevention of Micronutrient Deficiencies: Tools for Policymakers and Public Health Workers,Editors; Committee on Micronutrient Deficiencies, Institute of Medicine. national academy press Washington, D.C.1999. page no. 119,134, 144

[7] Sommer, A., et al. 1995. Impact of Vitamin A Supplementation on Childhood Mortality. The Aceh Study Group. Page no.14, 19,23,37,48,65,

[8] Andrew J. United Nations. 1990. Administrative Coordinating Committee, Subcommittee on Nutrition. Second Report on the World Nutrition Situation. Vol. 1, October 1990, p. 40,46, 54 Geneva: United Nations.

[9] Fernando E. Viteri, International Nutrition Planners Forum Workshop, "Elements of Successful Community Nutrition Programs," Seoul, Republic of Korea, August, 1996.

[10]Eduardo Villamor and Wafaie W. Fawzi, Vitamin A Saves Sight Departments of Nutrition, Epidemiology,Harvard School of Public Health, Boston, Massachusetts.

[11]Englberger L, Marks GC, Vitamin A deficiency among children--Federated States of Micronesia, Centers for Disease Control and Prevention (CDC). 2001 June.

[12] Neal A. Palafox, MD, MPH, Mary V. Vitamin A Deficiency, Iron Deficiency, and Anemia among Preschool Children in the Republic of the Marshall Islands. From the Department of Family Practice and Community Health, 2003.

\section{Author Profile}

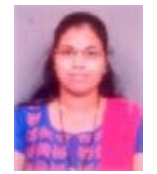

Mrs. Vishakha is the assistant professor, Department of Pediatrics, Godavari College of nursing Jalgaon, Maharashtra. She has been working in the field of pediatric specialty for the last 5 years. She interested all the aspect of child health care including growth and development, behavioral problems of children's and nutritional problem and their need for all the ages of pediatrics. 